\title{
Health consequences associated with frequent wheezing in adolescents without asthma diagnosis
}

\author{
K. Yeatts*, K. Johnston Davis", D. Peden", C. Shy*
}

Health consequences associated with frequent wheezing in adolescents without asthma diagnosis. K. Yeatts, K. Johnston Davis, D. Peden, C. Shy. (C) ERS Journals Ltd 2003. ABSTRACT: Using questions from the International Study of Asthma and Allergies in Childhood, this study evaluated the association between undiagnosed frequent wheezing and health consequences in adolescents.

The North Carolina School Asthma Survey provided self-reported questionnaire data on respiratory health from 122,829 children aged 12-14 yrs. The frequency of health consequences were compared among undiagnosed frequent wheezers, diagnosed asthmatics, and children with no wheezing symptoms or diagnosed asthma.

The odds of wheezing-related sleep disturbances, limited activities, and missed school were higher among undiagnosed frequent wheezers, relative to diagnosed asthmatics. The frequency of emergency room visits and hospitalisations did not differ substantially between the undiagnosed wheezing and diagnosed asthma groups, though the undiagnosed group was less likely to have visited a physician for wheezing in the past year.

Children with frequent wheezing symptoms but no asthma diagnosis experience substantial illness-related morbidity similar to that of diagnosed asthmatics. Undiagnosed frequent wheezers require more recognition from primary care physicians and need active disease management to reduce health consequences.

Eur Respir J 2003; 22: 781-786.

\begin{abstract}
*Dept of Epidemiology, School of Public Health, and Center for Environmental Medicine, Asthma and Lung Biology, School of Medicine, University of North Carolina at Chapel Hill, and "Worldwide Epidemiology, GlaxoSmithKline Research Triangle Park, $\mathrm{NC}$, USA.
\end{abstract}

Correspondence: K. Yeatts, Campus Box \#7435, School of Public Health, McGavran Greenberg Hall, University of North Carolina at Chapel Hill, Chapel Hill, NC 27599-7435 USA.

Fax: 19199662089

E-mail: Karin_Yeatts@unc.edu

Keywords: Adolescents, asthma, functional consequences, healthcare utilisation, wheezing

Received: October 212002

Accepted after revision: June 302003

The North Carolina Dept of Health and Human Services funded the implementation, data collection, and preliminary analyses of the statewide asthma survey. Further data analyses were funded by GlaxoSmithKline.
Asthma is the most common chronic illness in the USA affecting $\sim 5$ million children. Annually, asthma accounts for $\sim 15$ million outpatient visits, $>445,000$ hospitalisations and 1.2 million emergency room visits. During 1980-1996, the number of asthma-associated school absence days increased $>50 \%$ from 6.6 to 14.0 million [1]. Many of the published studies that focus on functional consequences of asthma morbidity are based on the National Health Interview Survey (NHIS) and National Health and Nutrition Examination Survey (NHANES III) data sets in which information is collected via parental report of physician-diagnosed asthma [2-6]. However, these estimates, by their design, will miss a large segment of the population suffering from asthma-like symptoms that have not been clinically diagnosed, resulting in a significant underestimation of the true impact of asthma in the population.

A growing body of evidence indicates that there are a substantial number of children who report asthma-like symptoms yet are not diagnosed with asthma [7-10]. However, there is a lack of information regarding functional consequences and healthcare utilisation rates in this population of children who wheeze, yet are not recognised as asthmatics.

The North Carolina School Asthma Survey (NCSAS), a

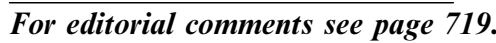

large population-based study of middle schoolchildren $(n=122,829)$, provides a unique opportunity to examine the functional consequences and healthcare utilisation of children reporting frequent asthma-like symptoms, without report of physician diagnosis of asthma. This study is distinct for several reasons compared with those previously published due to the following: 1) inclusion of large numbers of diverse groups of minority children (Native American, AfricanAmerican, Latin and Central American, and Asian children); 2) use of two different referent groups to represent both the clinical and public health perspective of asthma; 3) use of the internationally validated International Survey of Asthma and Allergies in Childhood (ISAAC) questionnaire that allows for identification of wheezing without diagnosis; 4) a large population-based rather than clinic-based sample; 5) simultaneous adjustment for other associated risk factors including medication use, allergies, active and passive smoking, and urban/rural areas, and socioeconomic status; and 6) comprehensive evaluation of both functional consequences and healthcare utilisation, each with three different measures.

\section{Methods}

NCSAS was a large population-based cross-sectional study conducted in the 1999-2000 school year, designed to obtain 
baseline surveillance data on asthma-like symptom prevalence in public school children aged 12-14 yrs. The UNC School of Public Health Institutional Review Board reviewed and approved the project. The target population was enumerated from 1999-2000 enrolment records kept by the North Carolina Dept of Public Instruction and included 565 public middle schools with 192,248 children.

The questionnaire used in the survey was adapted from ISAAC [11]. Both written and video symptom questions from the ISAAC survey were used [12-16]. The 12-14 yr age group was chosen to reflect the period when morbidity from asthma is common and to enable the use of self-completed questionnaires. The video symptom sequence showed five symptom scenes being experienced by adolescents: 1) wheezing at rest during the day; 2) wheezing after exercise; 3) waking at night by wheezing; 4) waking at night by cough; and 5) a severe wheezing attack with intercostal retractions. Questions were added regarding the functional health consequences of asthma and healthcare use. The questionnaire was administered in school to groups of children during class. To standardise the administration of the questionnaire, the entire questionnaire, including the ISAAC video wheezing sequence, was visually presented on a video screen and read aloud one question at a time with skip patterns emphasised [17]. Skip patterns were places in which children without symptoms or diagnosed asthma were told not to fill in specific questions related to asthma or wheezing. These children were reminded to wait and prompted to continue at the appropriate time.

Children were categorised by frequency of asthma-like symptoms with and without report of physician diagnosis of asthma. Three mutually exclusive groups were compared: 1) children with frequent wheezing symptoms and no diagnosis, whom the authors suspected might be comparable with diagnosed asthmatic children; 2) children who reported wheezing symptoms and a physician diagnosis of asthma; and 3 ) children with no symptoms or diagnosis ever (hereafter referred to as asymptomatics). A fourth group defined as infrequent wheezers, (children with infrequent wheezing symptoms and no physician diagnosis, $n=38,424$ ) was included for reference. This group was excluded from further statistical analyses as these children were beyond the scope and focus of this study. Frequent symptoms were defined as any of the video wheezing symptoms (at rest during the day, after exercise, waking at night, and severe wheezing attack with intercostal retractions) occurring once or more per month during the last 12 months. Episodic mild wheezing after exercise (once a month) was included in the definition "frequent" symptom. When these children were excluded from the statistical analyses, the associations were even more statistically significant.

Functional consequences were defined as the number of self-reported school absences, activity limitations, and sleep disturbance due to asthma-like symptoms (see Appendix for questions and response categories). Healthcare utilisation variables included the number of physician visits, emergency room visits and hospitalisation admissions for asthma-like symptoms. Frequencies for the functional consequences and healthcare use variables were tabulated for the four groups of children (table 1).

Outcome variables for the multiple logistic regression models compared the prevalence of the two highest response categories versus the lowest response category (none). The outcomes of activity limitations and school absence were categorised as $\geqslant 1$ days per week due to wheezing during the past 12 months versus none. For sleep disturbances, the outcome compared those with $\geqslant 1$ nights of sleep disturbances during the last 4 weeks versus none. For the healthcare utilisation variables, the outcome was categorised as three or more healthcare visits (physician, emergency room, or hospital) for wheezing, dry cough or breathing difficulties in the last 12 months compared with no visits.

Adjusted odds ratios (OR) of functional consequences and healthcare use for undiagnosed frequent wheezers were calculated against two different referent groups: 1) children with current diagnosed asthma; and 2) asymptomatic children. In addition, the authors calculated adjusted ORs comparing diagnosed asthmatics to asymptomatic children. Independent variables included in the model were age, sex, socioeconomic status, race, Latin and Central American ethnicity, any self-reported allergies (cat, dog, grasses, dust), current smoking, inhaler use, and regular source of healthcare for asthma or allergies.

\section{Results}

The survey response rate was $66.8 \%(128,568 / 192,248)$ for 7 th and 8 th grade children. There were no significant differences among the demographical variables of socioeconomic status (enrolment in the free/reduced school lunch programme), race, and sex for children who participated and those who did not ( $\mathrm{p}$-values from Chi-squared tests $0.66,0.61$, 0.58 , respectively.) Of the 128,568 participating children,

Table 1.-Asthma-like symptom categorisation (as reported in response to International Survey of Asthma and Allergies in Childhood video questions)

\section{Category}

Description

Frequent wheezers ${ }^{\#}$

Physician diagnosed asthmatics

Asymptomatic children

Infrequent wheezers
Children with a positive response to any of four video wheezing symptoms ${ }^{\text {o }}$ one or more times a month in the last 12 months and no report of physician diagnosed asthma

Children with a positive response to any of four video wheezing symptoms in last 12 months and a report of physician diagnosis of asthma

Children with no report of physician-diagnosed asthma and no positive responses to wheezing or coughing video questions

Children with only a positive response to video symptom of waking with cough in the last 12 months but no wheezing or physician diagnosis of asthma

Children with a positive response to any of four video wheezing symptoms or ever waking with cough in the past, but not in last 12 months

Children with a positive response to any of four video wheezing symptoms in the last 12 months but less frequently than once a month

\footnotetext{
\#: frequent defined as symptoms occurring once or more per month during the past 12 months. ${ }^{\top}$ : four video wheezing symptoms including scenes of: : frequent defined as symptoms occurring once or more per month during the past 12 months. : four video wheezing symptoms including scenes of:
1) wheezing at rest during the day; 2) wheezing after exercise; 3) waking at night by wheezing; or 4) a severe wheezing attack with intercostal
} retractions. 
Table 2.-Demographic characteristics by disease group, North Carolina School Asthma Survey, 1999

\begin{tabular}{|c|c|c|c|c|c|}
\hline & & $\begin{array}{l}\text { Undiagnosed frequent } \\
\text { wheezers }\end{array}$ & $\begin{array}{l}\text { Diagnosed current } \\
\text { asthmatics }\end{array}$ & Asymptomatic & $\begin{array}{l}\text { Infrequent } \\
\text { wheezers }\end{array}$ \\
\hline Subjects $n^{*}$ & & 7587 & 12174 & 64644 & 38424 \\
\hline \multirow{2}{*}{$\begin{array}{l}\text { Sleep disturbances at night due to } \\
\text { wheezing in the last } 4 \text { weeks }\end{array}$} & $<1$ night per week & 30 & 35 & 2 & 15 \\
\hline & $\geqslant 1$ nights per week & 17 & 15 & 0 & 4 \\
\hline \multirow{3}{*}{$\begin{array}{l}\text { Limited activities due to wheezing } \\
\text { in the last } 12 \text { months }\end{array}$} & $<1$ time per week & 23 & 33 & 1 & 10 \\
\hline & $\geqslant 1$ times per week & 10 & 14 & 0 & 2 \\
\hline & Almost daily & 5 & 5 & 0 & 1 \\
\hline \multirow{3}{*}{$\begin{array}{l}\text { Any school days missed due to } \\
\text { wheezing in the last } 12 \text { months }\end{array}$} & $<1$ day per month & 15 & 24 & 2 & 38 \\
\hline & $1-3$ days per month & 8 & 14 & 1 & 3 \\
\hline & $\geqslant 1$ days per week & 5 & 8 & 0 & 1 \\
\hline \multirow{3}{*}{$\begin{array}{l}\text { Physician visits due to wheezing } \\
\text { in the last } 12 \text { months }\end{array}$} & $1-2$ visits & 25 & 44 & 4 & 19 \\
\hline & $3-4$ visits & 5 & 18 & 0 & 3 \\
\hline & $5+$ visits & 3 & 9 & 0 & 1 \\
\hline \multirow{3}{*}{$\begin{array}{l}\text { Emergency room visits due to } \\
\text { wheezing in the last } 12 \text { months }\end{array}$} & $1-2$ visits & 7 & 22 & 1 & 4 \\
\hline & $3-4$ visits & 1 & 5 & 0 & 0 \\
\hline & $5+$ visits & 2 & 3 & 0 & 0 \\
\hline \multirow{3}{*}{$\begin{array}{l}\text { Hospitalisations due to wheezing } \\
\text { in the last } 12 \text { months }\end{array}$} & $1-2$ visits & 7 & 18 & 0 & 3 \\
\hline & 3-4 visits & 1 & 3 & 0 & 0 \\
\hline & $5+$ visits & 2 & 2 & 0 & 0 \\
\hline \multirow{4}{*}{$\begin{array}{l}\text { Inhaled medicine use in the last } \\
12 \text { months }\end{array}$} & $<1$ per month & 5 & 19 & 1 & 6 \\
\hline & $1-3$ days per month & 3 & 20 & 0 & 2 \\
\hline & $\geqslant 1$ times per week & 2 & 16 & 0 & 1 \\
\hline & Almost every day & 3 & 22 & 0 & 2 \\
\hline
\end{tabular}

Data are presented as $\%$ unless otherwise stated. *: percentages are rounded to the nearest whole number.

5,739 children were excluded from the analysis due to incomplete questionnaire data. The study population $(n=122,829)$ was $50 \%$ female, 27\% African-American, 9\% Latin and Central American, 1.91\% Asian/Pacific Islander, $96 \%$ aged $12-14$ yrs, and $33 \%$ of low socioeconomic status.

Factors independently associated with undiagnosed frequent wheezing versus asymptomatic children included female sex $(\mathrm{OR}=1.45,95 \%$ confidence interval $(95 \% \mathrm{CI})$ : $1.35-1.54)$, current smoking $(2.60,2.43-2.79)$, exposure to household smoke $(1.59,1.50-1.70)$, low socioeconomic status (1.52, 1.42-1.63), and African American (1.25, 1.15-1.34), Native American (1.35, 1.11-1.62), and Mexican American (1.32, 1.17-1.48) race/ethnicity. Urban residence showed a weak negative association $(0.91,0.85-0.96)$ [18].

Table 2 compares the frequencies of the functional consequences and healthcare utilisation due to wheezing for children with undiagnosed frequent wheeze, children with diagnosed asthma, and asymptomatic children. Asymptomatic children reported essentially no functional consequences or healthcare use related to wheezing.

To illustrate the relative impact of undiagnosed frequent wheezing, the authors compared undiagnosed frequent wheezers first to diagnosed asthmatics and then to children with no symptoms or diagnosed asthma (table 3 ). The odds of reported functional consequences were higher in undiagnosed frequent wheezers compared with diagnosed asthmatics. The second comparison among children with no symptoms quantifies the degree to which children with undiagnosed wheezing are impacted by their symptoms relative to a healthy population. Finally, a third comparison was made between diagnosed asthmatics and asymptomatic children, in order to demonstrate the impact of the diagnosed disease relative to the population free of respiratory illness.

OR and $95 \%$ CI in the first two columns of table 3 indicate that undiagnosed frequent wheezers were significantly more likely to report sleep disturbances $(1.9,1.7-2.1)$, limited

Table 3. - Adjusted associations of functional consequences and healthcare use with asthma-like symptoms, three comparisons

\begin{tabular}{lccc}
\hline & $\begin{array}{c}\text { Undiagnosed frequent wheezers } \\
\text { versus diagnosed asthmatics }\end{array}$ & $\begin{array}{c}\text { Undiagnosed frequent wheezers } \\
\text { versus asymptomatics }\end{array}$ & $\begin{array}{c}\text { Diagnosed asthmatics } \\
\text { versus } \text { asymptomatics }\end{array}$ \\
\hline $\begin{array}{l}\text { Sleep disturbances } \geqslant 1 \text { nights a week } \\
\text { due to wheezing in the last } 4 \text { weeks }\end{array}$ & $1.9(1.7-2.1)$ & $20.1(18.4-21.9)$ & $10.8(9.7-12.0)$ \\
$\begin{array}{l}\text { Limited activities } \geqslant 1 \text { times a week } \\
\text { due to wheezing }\end{array}$ & $1.6(1.4-1.9)$ & $40.1(33.3-48.7)$ & $24.5(19.7-30.5)$ \\
$\begin{array}{l}\text { 1 school days per month missed } \\
\text { due to wheezing in the last } 12 \text { months }\end{array}$ & $1.2(1.0-1.5)$ & $12.7(9.9-16.4)$ & $10.1(7.5-13.5)$ \\
$\begin{array}{l}\geqslant 3 \text { Physician visits due to wheezing } \\
\text { in the last } 12 \text { months }\end{array}$ & $0.6(0.5-0.7)$ & $9.8(10.2-15.2)$ & $20.7(16.8-25.6)$ \\
$\begin{array}{l}\geqslant 3 \text { emergency room visits due to } \\
\text { wheezing in the last } 12 \text { months }\end{array}$ & $0.9(0.6-1.1)$ & $10.0(6.5-15.7)$ & $10.8(7.1-16.7)$ \\
$\begin{array}{l}3 \text { hospitalisations due to wheezing } \\
\text { in the last } 12 \text { months }\end{array}$ & $0.9(0.7-1.2)$ & & $9.6(6.1-15.6)$ \\
\hline
\end{tabular}

Data are presented as odds ratio $(95 \%$ confidence interval). Prevalence odds ratios adjusted for age, sex, low socioeconomic status, any allergies, current smoking, source of care for asthma, and inhaler use during the last 12 months. Undiagnosed frequent wheezers are children with current frequent wheezing symptoms and no diagnosis of asthma. Asymptomatics are defined as children reporting no asthma-like symptoms or asthma diagnosis, ever $(\mathrm{n}=64,644){ }^{\#}$ : referent group is children with diagnosed asthma with current wheezing symptoms; ${ }^{\bullet}$ : referent group is asymptomatics. 
activities (1.6, 1.4-1.9), and missed school (1.2, 1.0-1.5) related to wheezing compared with diagnosed asthmatics. Undiagnosed frequent wheezers were almost half as likely to report physician visits $(0.6,0.5-0.7)$ compared with asthmatics. However, the odds for both emergency room visits $(0.9,0.6-1.1)$ and hospitalisations $(0.9,0.7-1.2)$ did not differ markedly between diagnosed asthmatics and undiagnosed frequent wheezers.

The second column of OR in table 3 compared the odds of functional consequences and healthcare utilisation for undiagnosed frequent wheezers relative to asymptomatic children. Undiagnosed frequent wheezers were more likely to experience sleep disturbances (20.1, 18.4-21.9), limited activities (40.1, 33.3-48.7), and missed school (12.7, 9.9-16.4) due to wheezing compared with asymptomatic children. The OR of healthcare utilisation for wheezing was 9.9-12.4 times higher for the undiagnosed frequent wheezers, compared with asymptomatic children.

Relative to asymptomatic children, diagnosed asthmatics were 10-24 times as likely to experience limited activities, sleep disturbances, and missed school (table 3). Healthcare utilisation was also more common among children with diagnosed disease. Diagnosed asthmatics were 20 times as likely to visit a physician compared with asymptomatic children and more than nine times as likely to report three or more emergency room visits or hospitalisation for wheezing compared with asymptomatic children.

\section{Discussion}

In these population-based analyses of children aged 12-14 yrs, the authors found that the odds of reporting functional consequences (sleep disturbances, school absences, activity limitations) were higher in undiagnosed frequent wheezers compared with diagnosed asthmatics. Frequent undiagnosed wheezers were equally likely to report emergency room visits, and hospitalisations due to wheezing compared with diagnosed asthmatics. However, the odds of physician visits for undiagnosed frequent wheezers were almost half that of diagnosed asthmatics, suggesting that undiagnosed frequent wheezers are not receiving maintenance care from a physician.

In the analyses of the current study, the authors included diagnosed asthmatics as a referent group to illustrate the increased odds of functional consequences in frequent undiagnosed wheezers, compared with diagnosed asthmatics. This comparison highlights the substantial burden of illness in undiagnosed frequent wheezers, yet they were half as likely as the diagnosed group to visit a physician. Using the asymptomatic group as a referent illustrated the substantial impact that undiagnosed frequent wheezing and diagnosed asthma have in the daily lives of affected children, compared with relatively healthy children.

Published literature on the health consequences of frequent wheezing in children with no asthma diagnosis is scant. The earliest report of undiagnosed asthma by SPEIGHT [9] in 1978, found that of the 34 children suspected to have undiagnosed asthma, 50\% missed $>6$ weeks of school, and 20\% (seven children) were hospitalised for wheezing. LOWE and BURR [19], 20 yrs later reported that in a cohort of British children with a history of allergy, 15/39 with wheezing and no diagnosis of asthma reported sleep disturbances. In Denmark, SIERSTED et al. [7] conducted a very comprehensive evaluation of undiagnosed asthma. However, the only health consequence measured was physical activity, with undiagnosed children 0.65 times as likely as diagnosed children to have had physical activity in the last 4 weeks. Hetvlik et al. [20] and
STRACHAN et al. [21] evaluated undiagnosed asthma in Norway and England, but only reported on medication use, while HiLL et al. [22] investigated school absences in Scotland. In the USA, SILVER et al. [23] found that $28 \%$ of children with wheezing compared with $42 \%$ of children with diagnosed asthma reported sleep disturbances one or more times per week on average, while CRAIN et al. [8] found that $18.6 \%$ and $18.4 \%$ of parents with either wheezing children or children with diagnosed asthma, respectively, reported that their child experienced one or more sleep disturbances due to wheeze in the last week.

The findings from the current study are likely to have been influenced by local factors and the structure and function of the national healthcare system (such as costs of healthcare utilisation, availability and access to healthcare, and the education of the health providers) and thus may not be generalised to European countries. This research may be limited to countries similar to the USA that do not have socialised medicine and fewer citizens with access to affordable medical care.

In comparison, the impact of diagnosed asthma on children's lives has been addressed previously [2, 3, 5]. The results from the current study for diagnosed asthmatics agree with these other studies. Using the 1988 NHIS database, FOWLER et al. [5] found that $42 \%$ of children missed school due to asthma in the last year, while in the current study $46 \%$ missed school due to asthma. The authors estimate activity limitation $(51 \%$ of children with diagnosed asthma) was higher than that of TAYLOR and NEWACHECK [2], who reported that $30 \%$ of children with asthma in the 1988 NHIS data had limitations in activities, but lower than the $71.5 \%$ reported by KAUR et al. [10]. Using data from the 1994-1995 NHIS study, NEWACHECK and HALFON [3] reported that children from low income households were 1.46 (95\% CI 1.2-1.76) times as likely to report disability due to asthma. Similarly, the current study found that children with diagnosed asthma of low socioeconomic status were 1.9 (1.7-2.1) times as likely to report sleep disturbances due to asthma.

Data from the current study were self-reported by adolescents aged 12-14 yrs. The asthma-like symptoms were assessed with the ISAAC questionnaire, which has been extensively validated [12-16, 24, 25]. Symptom data collected by directly interviewing adolescents has been found to be a more reliable source of information than parental report, the current standard for asthma in the NHANES III and NHIS in the USA $[25,26]$. The reliability and validity of the functional consequence and healthcare utilisation questions have been assessed [27]. The results from the current study for the burden of disease experienced by diagnosed asthmatic children agree with other published studies, further supporting the validity of this survey.

There are several strengths of the current study, the first being the comprehensiveness of the measures for both functional consequences (sleep disturbances, limited activities, and missed school all due to asthma-like symptoms) and healthcare use (physician and emergency room visits and hospitalisations) in three groups of children. Unlike other studies, the authors were also able to adjust for many independent risk factors associated with variations in asthma prevalence and morbidity (current smoking, socioeconomic status, sex, race, allergies, age, source of care, and medication use). Most of the research carried out to date has been clinicbased [7] and in children with diagnosed asthma [2-5, 28, 29], including only those whose parents seek care and have access to care. Clinic-based studies only measure the tip of the "iceberg" of asthmatic disease in the population.

Another strength of the current study is the use of the ISAAC questionnaire. The ISAAC $[12,13,23,30-32]$ has 
been conducted in 56 different countries, in 463,801 children [11] and another global survey with the ISAAC is currently underway. Reporting of wheezing symptoms using the ISAAC video has been validated with a high sensitivity (0.87) and specificity (0.75) when compared with a physician's diagnosis of clinically active asthma as a gold standard [13]. These studies determined that the video questionnaire was a reliable method for determining asthma prevalence [14-16, 24, 25, 31]. Recent research has shown that bronchial hyperresponsiveness (BHR) tests had a low sensitivity (0.35-0.47), whereas using asthma symptoms had high specificity $(>0.97)$ and sensitivity $(>0.7)$ in relation to clinical asthma, which makes them a better tool for asthma epidemiology than BHR [30, 32-34].

To the authors' knowledge this study is the first to evaluate multiple aspects of both functional consequences and healthcare use in children with undiagnosed frequent wheezing from a population-based sample. This research provides evidence that undiagnosed frequent wheezers require more recognition from primary care physicians and need active disease management. The results support the conclusion that the current published estimates of the prevalence and impact of asthma in the paediatric population are considerable underestimates. Undiagnosed frequent wheezers should be considered in estimates of the prevalence and impact of asthma in the population.

\section{Appendix: North Carolina School Asthma Survey functional consequences and healthcare use questions}

27. In the past 4 weeks, how often on average has your sleep been disturbed at night due to wheezing, dry cough, or breathing difficulties not due to a cold or chest infection?

None

$<1$ night per week

$\geqslant 1$ nights per week

28. In the last 12 months, how often did you limit your activities that you wanted to do (excluding school attendance) due to wheezing, dry cough, and/or breathing difficulties not due a cold or chest infection?

Never

$<1$ time per week

$\geqslant 1$ times per week

Almost daily

29. In the latest 12 months, how often did you miss school due to wheezing, dry cough, and/or breathing difficulties not due to a cold or chest infection?

Never

$<1$ day per month

1-3 days per month

$\sim 1$ day per week

$>1$ day per week

30. In the 12 months, how many times did you go to the doctor due to wheezing, dry cough and/or breathing difficulties?

0 (no visits)

$1-2$ visits

$3-4$ visits

$5+$ visits

31. In the last 12 months, how many times did you go to an emergency room due to wheezing, dry cough and/or breathing difficulties?

0 (no visits)
$1-2$ visits

$3-4$ visits

$5+$ visits

32. During the past 12 months, how many times were you admitted to a hospital due to wheezing, dry cough and/or breathing difficulties?

0 (no admissions)

1-2 admissions

3-4 admissions

$5+$ admissions

\section{References}

1. Mannino DM, Homa DM, Akinbami LJ, Moorman JE, Gwynn C, Redd SC. Surveillance for asthma- United States, 1980-1999. MMWR 2002; 51; Suppl. 1, 1-13.

2. Taylor WR, Newacheck PW. Impact of childhood asthma on health. Pediatrics 1992; 90: 657-662.

3. Newacheck PW, Halfon N. Prevalence, impact, and trends in childhood disability due to asthma. Arch Pediatr Adolesc Med 2000; 154: 287-293.

4. Haflon N, Newacheck PW. Childhood asthma and poverty: differential impacts and utilization of health services. Pediatrics 1993; 9: 55-61.

5. Fowler MG, Davenport MG, Garg R. School functioning of US children with asthma. Pediatrics 1992; 90: 939-944.

6. Halterman JS, Aligne CA, Auinger P, McBride JT, Szilagyi PG. Inadequate therapy for asthma among children in the United States. Pediatrics 2000; 105: 272-276.

7. Siersted H, Boldsen J, Hansen J, Mostgarrd G, Hyldebrandt N. Population-based study of risk factors for under diagnosis of asthma in adolescence: Odense schoolchild study. BMJ 1998; 316: 651-655.

8. Crain EF, Weiss KB, Bijur PE, Hersh M, Westbrook L, Stein RE. An estimate of the prevalence of asthma and wheezing among inner-city children. Pediatrics 1994; 94: $356-562$.

9. Speight AP. Is childhood asthma being under diagnosed and under treated? BMJ 1978; 2: 331-332.

10. Kaur B, Anderson HR, Burr M, Karkins LS, Strachan DP, Warner JO. Prevalence of asthma symptoms, diagnosis, and treatment in 12-14 year old children across Great Britain (International study of asthma and allergies in childhood ISAAC UK). BMJ 1998; 316: 118-124.

11. International Study of Asthma and Allergies in Childhood (ISAAC) Steering Committee. Worldwide variations in the prevalence of asthma symptoms: the International Study of Asthma and Allergies in Childhood (ISAAC). Eur Respir $J$ 1998; 12: 315-335.

12. Jenkins MA, Clarke JR, Carlin JB, et al. Validation of questionnaire and bronchial hyperresponsiveness against respiratory physician assessment in the diagnosis of asthma. Int J Epidem 1996; 25: 609-616.

13. Fuso L, De Rosa M, Corbo GM, et al. Repeatability of the ISAAC video questionnaire and its accuracy against a clinical diagnosis of asthma. Respir Med 2000; 94: 397-403.

14. Gibson PG, Henry R, Shah S, et al. Validation of the ISAAC video questionnaire (AVQ3.0) in adolescents from a mixed ethnic background. Clin Exp Allergy 2000; 30: 1181-1187.

15. Shaw R, Woodman K, Ayson M, et al. Measuring the prevalence of bronchial hyper-responsiveness in children. Int J Epidemiol 1995; 24: 597-602.

16. Shaw RA, Crane J, Pearce N, et al. Comparison of a video questionnaire with the IUATLD written questionnaire for measuring asthma prevalence. Clin Exp Allergy 1992; 22: $561-568$

17. Yeatts K, Shy CM, Wiley J, Music S. Statewide adolescent asthma surveillance. J Asthma 2000; 37: 425-434.

18. Yeatts KB, Davis KJ, Herget C, Sotir M, Shy CM. Who gets 
diagnosed with asthma? Frequent wheeze among adolescents with and without a diagnosis of asthma. Pediatrics 2003; 111: 1046-1054.

19. Lowe GL, Burr M. Undiagnosed and untreated wheezing in a cohort of adolescents with a family history of allergic disease. Br J Gen Prac 2001; 51: 664-665.

20. Hetlevik O, Ploen O, Nystad W, Magnus P. A follow-up of children with parentally reported episodes of wheeze without diagnosed asthma. Scand J Prim Healthcare 2000; 18: $122-126$

21. Strachan DP, Anderson HR, Limb ES, O'Neill A, Wells N. A national survey of asthma prevalence, severity, and treatment in Great Britain. Arch Dis Childhood 1994; 70: $174-178$.

22. Hill RA, Standen PJ, Tattersfield AE. Asthma, wheezing, and school absence in primary schools. Arch Dis Child 1989; 64: 246-251.

23. Silver E, Crain E, Weiss K. Burden of wheezing illness among US children reported by parents not to have asthma. J Asthma 1998; 35: 37-443.

24. Lai CK, Chan JK, Wong G, et al. Comparison of the ISAAC video questionnaire (AVQ3.0) with the ISAAC written questionnaire for estimating asthma associated with bronchial hyperreactivity. Clin Exp Allergy 1997; 27: 540-545.

25. Sole D, Vanna AT, Yamada E, Rizzo MCV, Naspitz CK. International Study of asthma and allergies in childhood (ISAAC) written questionnaire: validation of the asthma component among Brazilian children. J Invest Allergol Clin Immunol 1998; 8: 376-382.

26. Braun-Fahrlander CH, Gassner M, Grize L, et al. Comparison of responses to an asthma symptom questionnaire
(ISAAC core questions) completed by adolescents and their parents. Pediatr Pulmonol 1998; 25: 159-166.

27. Maier WC, Arrighi HM, Morray B, Llewllyn C, Redding G The impact of asthma and asthma-like illness in Seattle school children. $J$ Clin Epidemiol 1998; 51; 7: 557-568.

28. Diette GB, Markson L, Skinner EA, Nguyen TT, AlgattBergstrom P, Wu AW. Nocturnal asthma in children affects school attendance, school performance, and parent's work attendance. Arch Pediatr Adolesc Med 2000; 154: 923-928.

29. Forrest CB, Starfield B, Riley AW, Kang M. The impact of asthma on the health status of adolescents. Pediatrics 1997; 99: 1.

30. Pearce N, Pekkanen J, Beasley R. Role of bronchial responsiveness testing in asthma prevalence surveys. Thorax 2000; 55: 352-354.

31. Renzoni E, Forastiere F, Biggeri A, et al. on behalf of SIDRIA collaborative group. Differences in parental and self-report of asthma, rhinitis, and eczema among Italian adolescents. Eur Respir J 1999; 14: 597-604.

32. Beasley R, Lai CK, Crane J, Pearce N. The video questionnaire: one approach to the identification of the asthmatic phenotype. Clin Exp Allergy 1998; 28: Suppl. 1, 8 12.

33. Crane J, Beasley R, Stewart B, Shaw R, Pearce N, Burgess C. The international asthma video questionnaire for measuring asthma prevalence in different populations. Int Arch Allergy Immunol 1995; 107: 450-451.

34. Remes ST, Pekkanen J, Remes K, Salonen RO, Korppi M. In search of childhood asthma: questionnaire, tests of bronchial hyperresponsiveness, and clinical evaluation. Thorax 2002; 57: 120-126. 